\title{
Key success factors in implementing international public sector accounting standards
}

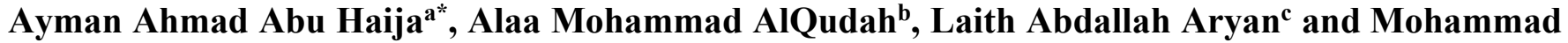 \\ Jamal Azzam ${ }^{b}$
}

accounting Department, Jadara University, Irbid, Jordan

${ }^{b}$ Accounting Department, Yarmouk University, Irbid, Jordan

${ }^{c}$ Department of Accounting, Ajloun National University, Jordan

\section{H R O N I C L E}

\section{Article history:}

Received: April 28, 2020

Received in revised format: July 302020

Accepted: September 6, 2020

Available online:

September 14, 2020

Keywords:

IPSAS

Key success factors

Public entities

Performance

\section{A B S T R A C T}

There is a worldwide debate regarding the implementation of IPSAS due to the potential obstacles that may face governments when they start moving to the full accrual basis. Of equal importance is that each country has its own needs and thus it must be examined separately to find out the factors that may motivate or limit the effective adoption of IPSAS. This study, therefore, aims to explore the key success factors when it comes to adopting IPSAS in Jordan. A 39-item questionnaire was devised and sent to 500 employees who were working in public entity departments. Only 326 questionnaires were returned, yielding a response rate of $65.2 \%$. The results suggested that the most important factors were local legislation and the infrastructure, while the training of staff came at the bottom of list. These results are important to regulators for drawing up a clear road map for transferring fully to IPSAS.

\section{Introduction}

Jordan began adopting wide economic reforms two decades ago, prompted by unprecedented budget deficits and a high unemployment rate. The political conditions in the Middle East placed burdens on Jordan's economy. Thus, the government needed an efficient information system to provide useful information for decision makers, which in turn might enable them to evaluate the government's performance. Rossi, Cohen, Caperchione, and Brusca (2016) argued that it was necessary to adopt relevant financial reporting standards to increase accountability and facilitate auditing procedures to help decision makers fight corruption. The International Public Sector Accounting Standards Board (IPSASB) highlighted the importance of moving toward full accrual basis IPSAS and claimed that it would enhance the usefulness of financial reporting and the decision-making process for all related parties in terms of doing business with public entities (Fahmid et al., 2019). They added that the accrual basis was better than the cash or modified cash basis in terms of providing information regarding financing decisions. The IPSAS explains that the accrual basis can provide users with sufficient information on assets and liabilities to demonstrate the accountability of the management to recognise the assets and labilities in financial statements (Whitefield \& Savvas, 2016). This will make the management more able to plan the needed funds for maintenance or replacing assets. Moving towards accrual basis requires public entities to maintain complete records of assets and liabilities to facilitate management control and help managers to compare the cost-benefit in delivering services (Brusca, Caperchione, Cohen, \& Manes-Rossi, 2018). Many

* Corresponding author.

E-mail address: aymanh@jadara.edu.jo (A. A. Abu Haija) 
researchers have argued that the accrual basis is better than the cash basis in terms of providing more relevant information; for instance, the World Bank (2004) asserted that IPSAS can enhance the quality, consistency and comparability of governmental financial reporting. Furthermore, it provides a more robust financial reporting system and it is useful in public sector reform. Similarly, Mhaka (2014) urged the government to adopt IPSAS to enhance the financial reporting of public entities in Zimbabwe. He argued that the adoption would help public entities manage internal and external debt and improve lenders' confidence in government performance. To achieve these benefits, Jordan adopted IPSAS in 2016 (ACCA, 2018) and is planning for full adoption in 2020 in an attempt to enhance the accountability and transparency of public sector entities' reporting. AlZubi (2015) claimed that Jordan had not adopted full IPSAS yet. He highlighted the need for more training of public entities employees and increased cooperation among related parties to enhance the transition to full accrual basis. This study is motivated by the lack of empirical studies on the key factors for successful implementation of IPSAS. Indeed, ACCA (2018) claimed that, while many developing countries intend to adopt IPSAS, only a few countries have completed the adoption successfully. It is remarkable that full adoption has been difficult for many countries and that it is still described as a 'work in progress'. This study will be beneficial to those countries by providing them with a clear road map to facilitate the transition to IPSAS.

IPSASB (2018) claimed that the developing countries are facing many constraints (e.g. willingness to change, unqualified staff and reliance on outside resources). Thus, it is recommended to use step-by-step adoption paths to reach full implementation successfully. Similarly, ACCA (2018) has argued that countries that have the intention of adopting accrual basis need to develop a clear strategy with a clear road map to implement IPSAS. It added that some countries have challenges, such as poor IT infrastructure and bad accounting systems. It is notable that the audit firms and donors can play an important role in enhancing the implementation through training of public entities employees and raising awareness of the benefits of using such public accounting standards. This study has used the key factors in successful implementation (namely, training, local legislation, infrastructure, external support, stakeholder engagement) as suggested in previous studies to draw up a road map to prepare public entities in Jordan to adopt IPSAS successfully.

\section{Literature Review and Hypotheses Development}

A review of the literature is needed to illustrate the actual status of IPSAS in Jordan and around the world, since such a topic is considered a new issue that may enhance the development of public sectors and introduce them as modern sectors (Ada, 2018). In this regard, Fahmid et al. (2019) claimed that adopting IPSAS is expected to lead to tighter reporting and more accurate information regarding government performance, and that governments can be evaluated accurately by several external groups. Hence, the transformation step to IPSAS has many benefits suggested by ACCA (2018); for instance: enhancing the government's efficiency, providing clear data regarding government activities and facilitating comparability among countries. Interestingly, the Bahraini public sector revealed that the transformation action has achieved some of the suggested benefits introduced by ACCA since they found that IPSAS techniques were beneficial in managing costs, enhancing the decision making process and helping them to be more accountable to other countries and their stakeholders (Elmezughi \& Wakil, 2018). In line with ACCA suggestions, Mnif Sellami and Gafsi (2019) found a positive role of external funding, the openness, and the willingness to follow and adopt IPSAS based on a sample of 110 countries. Furthermore, well-trained employees and technological resources were the most important factors needed to transfer to a good adoption of IPSAS in the public higher education institutions in Thailand (Bell, Hoque, Upping, \& Oliver, 2012). Patrick, Danladi, Caleb, and Linda (2017) analysed the cost-benefit relationship in terms of adopting IPSAS in Nigeria. Targeting the accountants' perceptions, he concluded that the immense benefits of IPSAS had overridden the adoption costs and that the quality of financial reports has been enriched to become comparable with other countries' reports. Similarly, Lampe, Hilgers, and Ihl (2015) concluded that the magnitude of the initiatives taken by the German government was efficacious in reducing costs by adopting accruals techniques compared with cash techniques. Alongside the previous conclusion, the transformation actions to adopt IPSAS suggestions have enhanced the level of published information in Germany, specifically with regard to the financial performance, instead of disclosing information that explains bank transactions regarding government actions (Dabbicco, 2015). Rossi et al. (2016) claimed that harmonising the public sector standards through the European countries by encouraging them to adopt IPSAS might pave the way to preparing comparable financial reports. In line with this argument, the Malaysian public sector employees were disposed to adopt the accruals technique, since IPSAS is expected to enhance the transparency and accountability of governmental reports. However, Azmi and Mohamed (2014) were concerned about the lack of qualified employees who are experienced in IPSAS techniques. Jorge, Jesus, and Laureano (2016) found that the effects of IPSAS adoption in terms of budgetary deficit- surplus adjustments were pronounced, but more efforts were needed to enhance the quality of the government's financial reports.

Ijeoma and Oghoghomeh (2014) focused on whether the transparency and accountability of the public sector reports would be affected by IPSAS. They found IPSAS to be an efficient tool to introduce financial reports. Additionally, Ilie and Miose (2012) argued that IPSAS implementation provides more comparable and recognised reports internationally. They added that using IPSAS for public entities increases the transparency and the quality of financial reporting. However, IPSAS may face several challenges that constrain efficient adoption. For instance, ACCA (2018) revised the practical implementation of IPSAS in the 
world, and concluded that the implementation of IPSAS faces many challenges, such as resistance to change, poor IT infrastructure, poor book keeping practices and, in general, accounting information systems failure. For example, the competence of the governmental employees and the low level of their openness to accepting IPSAS recommendations were the main drawbacks in the Indonesian context. Furthermore, the absence of fertile ground of legislation that might support IPSAS was found to minimise the quality of reports prepared by governments (Gamayuni, 2019). Additionally, Elmezughi and Wakil (2018) aimed to determine the benefits and obstacles of moving towards full accrual basis in Bahrain. Indeed, there were many obstacles to achieving these benefits, including lack of employees' knowledge of accrual basis and problems of fixed assets valuation. Additionally, the readiness of the governmental employees and the experience of internal audit departments were the main contingent factors needed to adopt IPSAS efficiently (Mustapha, Ismail, \& Ahmad, 2017). In the same vein, Ranjani and Neba (2016) claimed that the financial and accounting systems were very weak to support the Nigerian initiatives which aimed to enhance the adoption of IPSAS. Whitefield and Savvas (2016) explored the shortfalls that might face IPSAS adoption in Kenya; he concluded that the shortage of financial and technological resources and the absence of the necessary institutional settings were the main obstacles to moving to IPSAS. However, the Iraqi context added another factor that might prevent IPSAS from being an efficient bridge to transfer from cash to accruals basis. Indeed, Alshujairi (2014) concentrated on the importance of the presence of well-trained staff that can show a satisfactory level of IPSAS understanding to guarantee an effective level of adoption.

\section{Underpinning Theories}

Institutional theory shows how organisations and countries may react under the pressure to adopt a new set of regulations, such as IPSAS, to maximise countries' and organisations' acceptance worldwide. Judge, Li, and Pinsker (2010) claim that the umbrella of institutional theory may create an isomorphism among organisations and countries in terms of adopting the new regulations. More specifically, DiMaggio and Powell (1991) suggested three significant levels of isomorphism. Firstly, under coercive isomorphism, countries and organisations try to maximise their adoption of the new laws or regulations as a response to pressures exerted by various parties, such as stakeholders, donors or other international groups, by which highly accountable and accurate financial reports are needed to evaluate the financial positions of such countries or organisations and to guarantee sufficient levels of assistance in terms of finance (Baskerville \& Grossi, 2019). In other words, countries may be incentivised to show an even-handed level of IPSAS adoption to pave the way to gaining a sufficient level of loans to secure the needed resources for developing their countries. Secondly, the mimetic isomorphism level suggests that countries are motivated to copy (imitate) other countries' practices related of regulations adoption as they have been seen as felicitous and more accepted economies in comparison with other countries. Following this perspective, countries seek to be globalised and attractive for foreigners to invest more in their countries, since such international regulations allow comparable reports and may facilitate the transfer of investments across borders; therefore, countries seek to adopt an accepted set of practices (IPSAS) to present their economies as successful targets for external groups (Judge et al., 2010). The third level of isomorphism is normative. This stand of institutional theory presents the need to professionalise practices and qualifications (i.e. educational levels) and the necessary infrastructure (i.e. technology) to create a stable environment that supports the adoption of regulations (DiMaggio \& Powell, 1991; Kamal Hassan, 2008). In this regard, Gomes, Fernandes, and Carvalho (2015) asserted that activating new regulations, such as IPSAS, is needed to legitimate countries' practices by modifying the professional issues to meet the pressures of global needs. Hence, this theory outlines the theoretical umbrella of adopting IPSAS. Therefore, some countries may adopt such standards to cope with the global pressures to guarantee a smooth flow of external loans from international donors. In contrast, some countries may imitate other countries that have successfully adopted IPSAS, in order to appear to be loyal and active countries in terms of adopting new regulations.

The main goal of any representative group is to maximise the benefits and the welfare of their principals (AlQudah, Azzam, Haija, \& AlSmadi, 2020). Therefore, governments are motivated to adopt the most suitable and effective regulations in order to achieve this key goal. Hence, the adoption of successful regulations is a vital approach to restrict economic downturns and as a way to assign financial and other resources effectively. Hence, the public interest theory may support the adoption of IPSAS, for instance, since such a theory is expected to hinder the presence of information asymmetry problems by providing accountable and accurate reports for countries in a way that achieves the principals' goals (Matekele \& Komba, 2019; Posner, 1974). Motivated by this suggestion, countries are under pressure to maximise the welfare of their principals by harmonising their accounting practices in alignment with the global set of regulations to avoid market failures (Mnif Sellami \& Gafsi, 2019). Additionally, Kaya and Koch (2015) claimed that countries with no clear set of regulations prefer to activate and adopt the most commonly agreed regulations, such as IPSAS, in order to build a solid ground for their economies and to protect the interests of the public in a way that guarantees welfare maximisation. Based on the previous discussion and underpinning theories, the hypotheses of the current study are developed as follows:

$\mathbf{H}_{1:}$ Training plays a vital role in enhancing the successful implementation of IPSAS.

$\mathbf{H}_{2}$ : Local legislation plays a vital role in enhancing the successful implementation of IPSAS.

H3: Infrastructure plays a vital role in enhancing the successful implementation of IPSAS. 
H4: External support plays a vital role in enhancing the successful implementation of IPSAS.

H5: Stakeholder engagement plays a vital role in enhancing the successful implementation of IPSAS.

\section{Methodology}

This study has five hypotheses to explore government employees' perceptions regarding the key success factors for implementing IPSAS. We have developed a 39-item questionnaire and sent it to 500 employees who were working in public entities departments; for instance, the Ministry of Finance, the Central Bank of Jordan, the General Budget Department, the Customs Department and the General Supplies Department. Only 326 questionnaires were returned, yielding a response rate of $65.2 \%$.

\subsection{Questionnaire Validity and Reliability}

The questionnaire was sent to five experts to evaluate the suitability and clarity of the questions. After considering all the recommendations, we ran a pilot study on 30 public entities' employees. The reliability of the questionnaire was tested using Cronbach's alpha. According to Hair Jr, Page, and Brunsveld (2019), this instrument is considered to be acceptable if the alpha values are between 0.6 and 0.7 , and highly reliable if the values are above 0.7 . Table 1 shows the reliability coefficients for the variables of the study. It shows that the coefficients of Alpha are more than 0.7 , which is considered highly reliable.

Table 1

\section{Reliability Coefficients}

\begin{tabular}{lll}
\hline No. of Items & Variables & Cronbach's Alpha \\
\hline 6 & Training & 0.843 \\
6 & Local Legislation & 0.854 \\
6 & Infrastructure & 0.722 \\
6 & External support & 0.765 \\
6 & Stakeholder engagement & 0.799 \\
8 & IPSAS & $0 . .802$ \\
\hline
\end{tabular}

\subsection{Factor Analysis}

Before running factor analysis, the assumptions of normality, homoscedasticity and linearity were checked. Kaiser Meyer Olkin (KMO) and Bartlett's test of sphericity were used to perform factor analysis (Kaiser, 1974). Table 2 shows the KMO guide to interpreting the KMO test.

Table 2

KMO Test Guide

\begin{tabular}{ll}
\hline KMO & Opportunity for factor analysis \\
\hline .90 to 1.00 & Marvellous \\
.80 to .89 & Meritorious \\
.70 to .79 & Middling \\
.60 to .69 & Mediocre \\
.50 to .59 & Miserable \\
\hline Below .50 & Should be excluded \\
\hline
\end{tabular}

According to Hair Jr et al. (2019), the number of factors is defined as follows: (1) eigenvalue should be greater than 1.0; (2) the factors have substantial amounts of common variance as displayed in the screen test. Then the variables that have no clear loading on the factor were deleted. Finally, the factor was labelled based on the higher loading items. The following tables illustrate the results of the factor analysis:

\subsubsection{Training}

Table 3 shows that factor analysis was suitable to be performed on training because the KMO was 0.772 and the sphericity test was significant at $\leq .005$. The items that were loaded into the training factor explained $44.23 \%$ of the total variance. The table shows that the loading on this factor ranges from 0.801 to 0.598 and it shows a very clean result. Only one item was removed (Question no. 1: "providing training to employees helps enhance their ability to adopt IPSAS") since it was not loaded on the component obtained. 
Table 3

\begin{tabular}{|c|c|c|}
\hline Items & Component & Reliability \\
\hline Training & & 0.856 \\
\hline 1. Training in IPSAS is needed to enable the governmental entities' employees to understand it & .801 & \\
\hline Participating in courses and workshops on IPSAS is necessary to implement IPSAS successfully & .791 & \\
\hline Governmental entities keep their employees updated regarding the IPSAS updates & .743 & \\
\hline Governmental entities hire well-educated and trained people & .623 & \\
\hline 5. Governmental entities have well-trained people to help in the implementation of IPSAS & .598 & \\
\hline Total Variance Explained $\quad 44.23 \%$ & & \\
\hline Kaiser-Meyer-Olkin Measure of Sampling Adequacy & & \\
\hline Bartlett's Test of Sphericity & & \\
\hline
\end{tabular}

\subsubsection{Local Legislation}

The KMO test is 0.692 and this exceeds the recommended value of 0.6 and above. Bartlett's Test of Sphericity was also statistically significant, suggesting that factor analysis was suitable to be performed on this variable. Table 4 shows the items and loading for each item. The loading on this factor ranges from 0.844 to 0.668 . This factor includes six items describing information about local legislation.

\section{Table 4}

Factor Loading on Local Legislation

\begin{tabular}{|c|c|c|}
\hline Items & Component & Reliability \\
\hline Local Legislation & & 0.847 \\
\hline 1. Related parties had a clear road map including all steps and procedures for adopting IPSAS & .844 & \\
\hline Related parties issued a periodical report which includes the stage of completion on IPSAS implementation & .809 & \\
\hline Related parties corrected and mitigated the deviations in the adoption process for IPSAS & .756 & \\
\hline Related parties issued a periodical report including the deviations & .743 & \\
\hline Related parties adhered to the road map to transform for full adoption of IPSAS & .711 & \\
\hline 6. Local legislation was well-prepared to adopt IPSAS & 668 & \\
\hline Total Variance Explained & & \\
\hline Kaiser-Meyer-Olkin Measure of Sampling Adequacy & & \\
\hline Bartlett's Test of Sphericity & & \\
\hline
\end{tabular}

\subsubsection{Infrastructure}

Table 5 shows that factor analysis was suitable to be performed on infrastructure. The KMO test was 0.654 and the sphericity test was significant at $\leq .005$. The items that are loaded into this factor explained $45.22 \%$ of the total variance. Loading on this factor ranges from 0.861 to 0.652 . This factor includes four items describing information about infrastructure. Two items were removed because they were not loaded clearly on the components obtained (Question no 3: "using advanced technology helps in enhancing the implementation of IPSAS" and Question no. 6: "the existence of networks facilitates the adoption of IPSAS"). However, other component matrices had very clean results and were strongly loaded only on one component.

\section{Table 5}

Factor Loading on Infrastructure

\begin{tabular}{lcc}
\hline Items & Component & Reliability \\
\hline Infrastructure & .861 & 0.715 \\
1. Governmental entities have sufficient hardware and software to implement IPSAS & .764 & .709 \\
2. Governmental entities have sufficient internal and external networks to facilitate the adoption of IPSAS & .652 \\
\hline 3. The systems are continuously updated to comply with the requirements of IPSAS implementation & \\
4. The accounting records and forms are adjusted to comply with IPSAS implementation & $45.22 \%$ & .654 \\
\hline Total Variance Explained & .000 & \\
Kaiser-Meyer-Olkin Measure of Sampling Adequacy & & \\
Bartlett's Test of Sphericity &
\end{tabular}

\subsubsection{External Support}

The KMO test was 0.672 for this variable, and the sphericity test was significant at $\leq .005$. The items that are loaded into this factor explained $44.12 \%$ of the total variance. This means that factor analysis was suitable to be performed on verifiability. Table 6 shows the factors loaded on external support. As shown in the table, loading on this factor ranges from 0.822 to 0.603. This factor includes five items describing information about external support. One item was removed because it was not loaded clearly on the components obtained (Question no 4: "communication with external bodies (i.e. external auditors) will enhance the governmental entities' employees' experience in adopting IPSAS”). The other component matrices had very clean results and were strongly loaded only on one component. 
Table 6

Factor Loading on External Support

\begin{tabular}{|c|c|c|c|}
\hline \multicolumn{2}{|c|}{ Items } & Component & Reliability \\
\hline \multicolumn{3}{|c|}{ External Support } & 0.771 \\
\hline 1. & Public entities cooperate with external experts to help in IPSAS adoption & .822 & \\
\hline 2. & Public entities cooperate with external experts to train the employees on IPSAS implementation & .755 & \\
\hline 3. & $\begin{array}{l}\text { Public entities cooperate with professional bodies (i.e. external auditors) to help the employees to understand and } \\
\text { apply IPSAS }\end{array}$ & .692 & \\
\hline 4. & Public entities cooperate with international bodies to help the employees to understand and apply IPSAS & .651 & \\
\hline 5. & Public entities recruiting well-qualified people to help the employees to understand and apply IPSAS & .603 & \\
\hline \multicolumn{4}{|c|}{ Total Variance Explained $44.12 \%$} \\
\hline \multicolumn{2}{|r|}{ Kaiser-Meyer-Olkin Measure of Sampling Adequacy $\quad .672$} & & \\
\hline \multicolumn{2}{|r|}{ Bartlett's Test of Sphericity } & & \\
\hline
\end{tabular}

\subsubsection{Stakeholder Engagement}

Table 7 shows that factor analysis was suitable to be performed on stakeholders. The KMO test was 0.683 and the sphericity test was significant at $\leq .005$. The items that are loaded into this factor explained $43.44 \%$ of the total variance. As shown in the table, loading on this factor ranges from 0.862 to 0.604 . This factor includes six items describing information about stakeholder engagement. All component matrices had very clean results and were strongly loaded only on one component.

Table 7

Factor Loading on Stakeholder Engagement

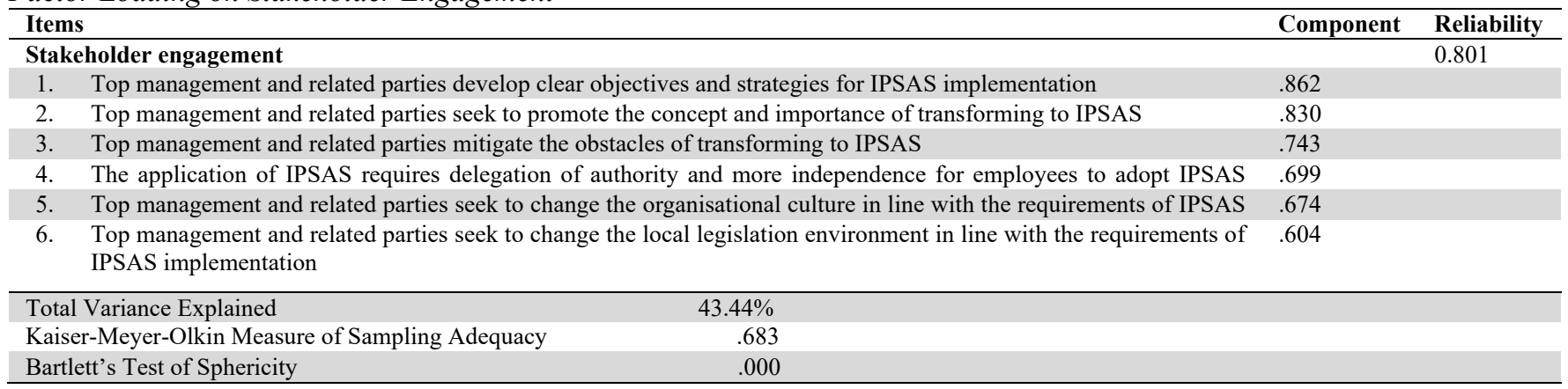

\subsubsection{IPSAS}

The KMO test was 0.685 and the sphericity test was significant at $\leq .005$. This implies that factor analysis was suitable to be performed on IPSAS. The items that are loaded into this factor explained $46.87 \%$ of the total variance. Table 8 shows the factors loaded on IPSAS. The loading on this factor ranges from 0.799 to 0.609 . This factor includes seven items describing information about IPSAS. One item was removed because it was not loaded clearly on the components obtained (Question no. 5: "Using IPSAS enables users to utilise financial statements easily"). However, other component matrices had very clean results and were strongly loaded only on one component.

\section{Table 8}

\section{Factor Loading on IPSAS}

\begin{tabular}{|c|c|c|}
\hline Items & Component & Reliability \\
\hline IPSAS & & 0.813 \\
\hline $\begin{array}{l}\text { 1. The transition to IPSAS helps the public sector by making government financial reports more useful to financial } \\
\text { statements users }\end{array}$ & .799 & \\
\hline 2. The transition to IPSAS promotes transparency and accountability in financial reporting & .765 & \\
\hline Using IPSAS provides better information to decision makers & .708 & \\
\hline Using IPSAS helps the public sector to focus on the actual performance of government units & .691 & \\
\hline $\begin{array}{l}\text { The transition to IPSAS helps the government to obtain information easily and compare the performance of government } \\
\text { units }\end{array}$ & .684 & \\
\hline The transition to IPSAS helps the public sector to obtain feedback on the performance of government units & .653 & \\
\hline 7. The transition to IPSAS boosts the confidence of local and foreign investors in the government's economic performance & .609 & \\
\hline $\begin{array}{l}\text { Total Variance Explained } \\
\end{array}$ & & \\
\hline Kaiser-Meyer-Olkin Measure of Sampling Adequacy & & \\
\hline Bartlett's Test of Sphericity & & \\
\hline
\end{tabular}


After running factor analysis, it is necessary to rerun the reliability test again to check for the reliability of the survey instrument. According to Hair Jr et al. (2019), the perfect measure of a concept needs more than one item. Moreover, according to Nunnally (1978), to assess the reliability of the survey instrument, the inter-item analysis can be used to test the scale's internal consistency. Hence, Cronbach's alpha is considered an adequate indicator of the internal consistency and the reliability of the survey instrument (Sekaran \& Bougie, 2016). Tables 3 to 8 above show the reliability coefficients of the measurement of each variable. The tables show that the Cronbach's alphas ranged from 0.856 to 0.715 , which exceeded the minimum value of 0.7 to be acceptable. This means that the instruments used to measure the variable were acceptable and the data were later used for further analysis.

Criterion validity analysis was conducted by using the dependent and the independent variables. Pearson's correlation was used to quantify the strength of relationship between two variables. According to Hair et al. (2019), there is a high collinearity between two variables when the correlation is above 90 percent. So, any correlation that is significant at 0.01 level expresses a 99 percent certainty that the correlation between two variables is not random, and the same applies for a significance level of 0.05 , which expresses a 95 percent certainty.

To test collinearity, this study depends on the tolerance (TOL) and the variance inflation factor (VIF). The TOL indicates the effect of the other independent variables on the standard error of regression coefficient. According to Hair et al. (2018), TOL should be above 0.10 and the VIF should be less than 10 to indicate no collinearity or multi-collinearity. As shown in Table 9, there is no collinearity or multi-collinearity among the variables of this study. The table shows that the values of VIF range from 2.454 to 4.389 and the values of TOL range from 0.228 to 0.408 .

Table 9

Multicollinearity Diagnoses

\begin{tabular}{lll}
\hline Variables & Tolerance & VIF \\
\hline Stakeholder Engagement & .258 & 3.872 \\
Local Legislation & .228 & 4.389 \\
External Support & .261 & 3.825 \\
Infrastructure & .272 & 3.677 \\
Training & .408 & 2.454 \\
\hline
\end{tabular}

The population of this study was around 1,100 employees. According to Sekaran and Bougie (2016), sampling is selecting a sufficient number of respondents from a population. In doing so, we have sent the questionnaire to 500 employees in the related public entities. Only 326 questionnaires were returned, with a $65.2 \%$ response rate. Fig. 1 highlights the demographic profile of the respondents.

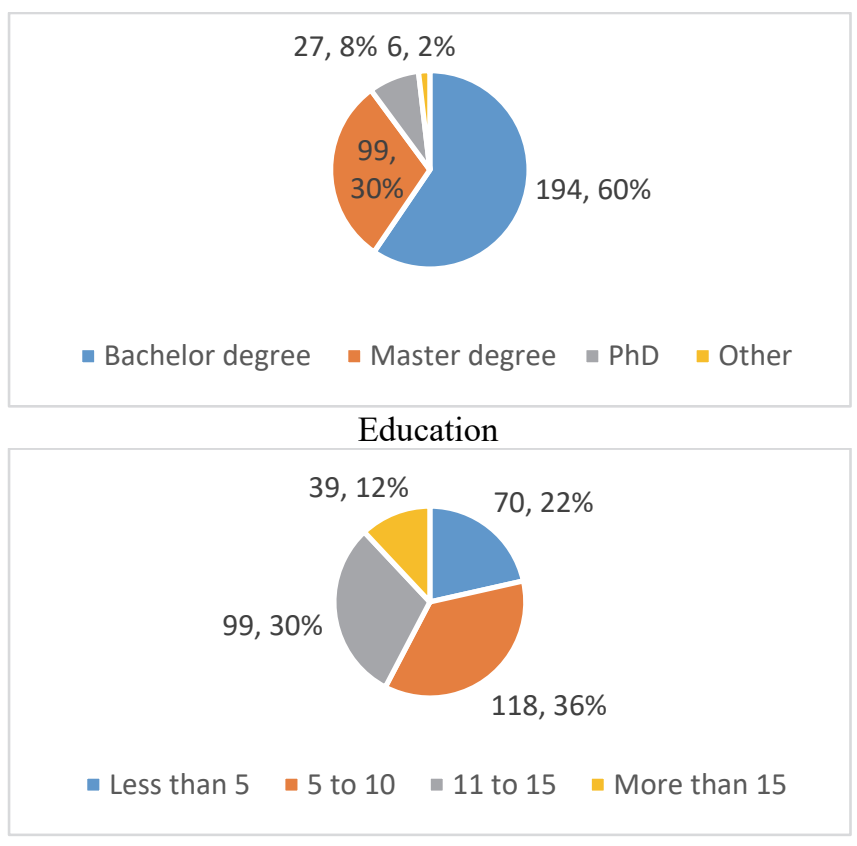

Years of Experience

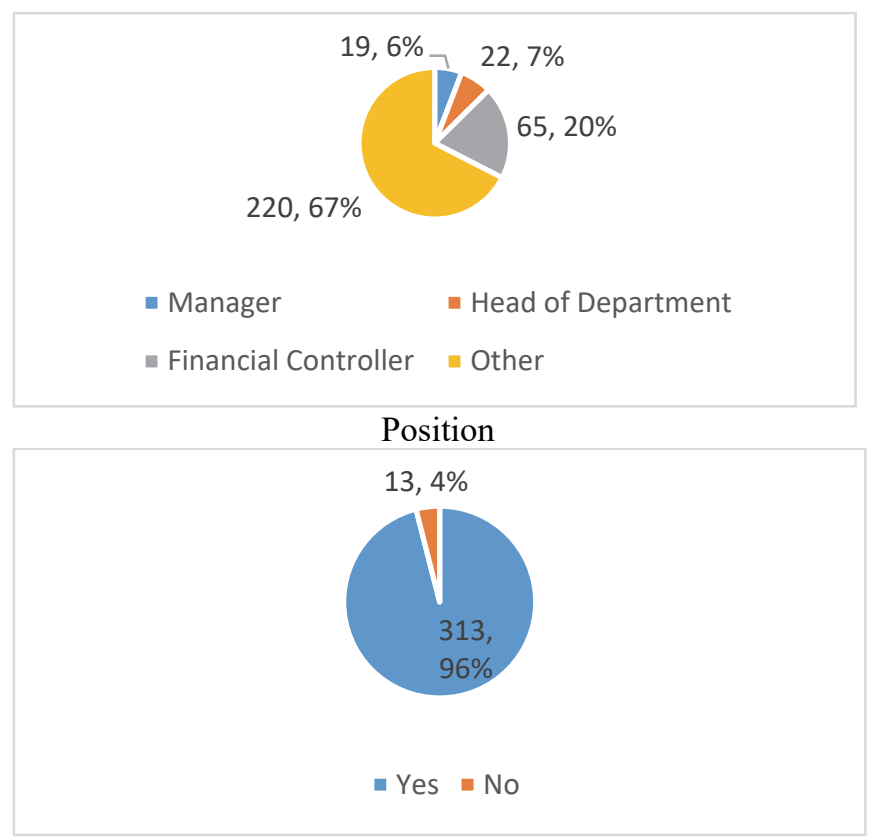

Training on IPSAS

Fig. 1. Personal characteristics of the participants 
The figure shows that the majority of public entities employees held a bachelor $(59.5 \%$ - 194) degree. Those with a master's degree are $30.4 \%(99)$. The remaining employees either had a PhD $(8.3 \%-27)$ or other degree $(1.8 \%-6)$. Regarding the position, 5.8\% (19) are managers and 6.7\% (22) of the respondents are heads of departments, while 19.9\% (65) are financial controllers and the remaining $76.5 \%$ (220) are working in different positions. The results show that $21.5 \%$ (70) employees have experience of less than five years, while the majority have a medium experience, $36.2 \%(118)$ have more than 5 and less than 10 years' experience and 30.4\% (99) have experience of from eleven to fifteen years. The remaining $12 \%$ (39) have more than fifteen years' experience. Table 10 shows that most public entities employees $(96 \%-313)$ have attended a training on IPSAS.

\section{Table 10}

Means and Standard Deviations of the Variables

\begin{tabular}{llll}
\hline Variables & Total number of items & Mean $^{\text {a }}$ & \\
\hline Stakeholder Engagement & 6 & 3.9011 & .88522 \\
Local Legislation & 6 & 3.8288 & .90049 \\
External Support & 5 & 3.8819 & .90684 \\
Infrastructure & 4 & 3.8251 & .84338 \\
Training & 5 & 3.8266 & .76743 \\
IPSAS & 7 & 3.9158 & .86389 \\
\hline
\end{tabular}

Note: ${ }^{\text {a }} 1$ = strongly disagree, $2=$ disagree, $3=$ neutral, $4=$ agree, $5=$ strongly agree

Table 10 exhibits the mean and standard deviation of Jordanian governmental entities employees' responses who in general had a favourable perception of IPSAS adoption. The respondents also highlighted the important role that the stakeholders can play in implementing IPSAS successfully. The respondents also perceived the other factors favourably (i.e. local legislation, external support, infrastructure and training) as vital factors to move to accrual basis properly.

\subsection{Regression Results}

The data must be checked for linearity, normality and homoscedasticity before a regression test is performed. Hair et al. (2018) stated that normality is assumed when the skewness and the kurtosis are between \pm 1.96 at alpha value .05 and \pm 2.58 at alpha .01 , respectively. The results of the skewness test ranged from -1.304 to -0.970 and the kurtosis values ranged from 0.128 to 1.101 , indicating that the data were normally distributed. Table 11 illustrates the results of multiple regression on the relationship between stakeholders, local legislation, external support, infrastructure and training and the implementation of IPSAS. The results show that local legislation is the most important variable $(b=0.556 \mathrm{p}>.001)$ and related positively to the implementation of IPSAS. This implies that the government should modify the legislation to pave the way to successfully implementing IPSAS. Infrastructure was found to be positive and significant $(b=0.431 \mathrm{p}>.001)$, which means that the respondents perceive the infrastructure as a significant factor to implement IPSAS due to the need for suitable infrastructure to help the public entities employees in the transformation process. The stakeholders and external support came in third and fourth ranks respectively. The respondents perceived the two variables as almost equal in importance $(b=0.311 \mathrm{p}>.001)(b=0.309 \mathrm{p}>.001)$, which in turn highlights the role of external support and stakeholder resources in enhancing the implementation of IPSAS. Finally, training has a positive and significant role $(b=0.299 \mathrm{p}>.050)$ and ranked as the least important factor.

\section{Table 11}

Results of the Regression test

\begin{tabular}{llll}
\hline Hypothesis & Variable & Coefficients Model One & Results \\
\hline$H 1$ & Training & $0.229^{* *}$ & Accepted \\
$H 2$ & Local legislation & $0.556^{* * *}$ & Accepted \\
$H 3$ & Infrastructure & $0.431^{* * *}$ & Accepted \\
$H 4$ & External support & $0.309^{* * *}$ & Accepted \\
$H 5$ & Stakeholder engagement & $0.311^{* * *}$ & Accepted \\
\hline Adjusted $R^{2}$ & 74.6 & & \\
\hline$* *, * * *$ denote significance at 5 and 1 percent, respectively & &
\end{tabular}

The results of this study are in line with IPSASB (2018), which emphasised the need for well-qualified staff and the support of outside resources to implement IPSAS successfully, especially in developing countries. Moreover, ACCA (2018) claimed that the existence of good infrastructure and getting external support from professional bodies will help in accrual basis transformation.

\section{Concluding Comments}

This study aimed to explore the key success factors in adopting IPSAS, namely training, local legislation, infrastructure, external support and stakeholder engagement. The cost-benefit factor is not examined in the current study, since Jordan is still in the early stages of adoption and it is difficult to get true evidence on this factor. 
The results of this study show a positive and significant relationship between training, local legislation, infrastructure, external support, stakeholder engagement and IPSAS. Such results were expected, since the variables of this study were carefully chosen from previous studies, and the aim of this study was to get a clear view of the importance of variables to help regulators and policymakers draw up a clear road map for IPSAS implementation. As discussed previously, the two most important variables are local legislation and infrastructure. This makes sense due to the need for suitable legislation and infrastructure to enable the public entities employees to start working on IPSAS transformation. External support and stakeholder engagement came in the second level. They are needed to share their resources and experience and to enhance the adoption process. Notwithstanding that training came at the bottom of list, most of the respondents had training in IPSAS, but they perceived the other factors as more important due to the fact that, initially, the implementation of IPSAS needs suitable legislation and infrastructure. It is recommended to explore the cost-benefit factor in other countries that have adopted full IPSAS, since the benefits cannot be quantified easily at this early stage of adoption in Jordan. It is recommended to assess the impact of IPSAS implementation on the financial reporting quality of public entities.

\section{References}

ACCA. (2018). IPSAS implementation: current status and challenges: The Association of Chartered Certified Accountants London.

Ada, S. S. (2018). The Implementation Process of IPSAS. Ghent University.

Al-Zubi, Z. (2015). The extent of applying the International Public Sector Accounting Standards by the Jordanian Public Sector.

AlQudah, A. M., Azzam, M. J., Haija, A. A. A., \& AlSmadi, S. A. (2020). The role of ownership map in constraining discretionary loan loss-provisions decisions in Jordanian banks. Cogent Business \& Management, 7(1), 1752604.

Alshujairi, M. H. A. (2014). Government accounting system reform and the adoption of IPSAS in Iraq. Research Journal of Finance and Accounting, 5(24), 1-20.

Azmi, A. H., \& Mohamed, N. (2014). Readiness of Malaysian public sector employees in moving towards accrual accounting for improve accountability: The case of Ministry of Education (MOE). Procedia-Social and Behavioral Sciences, 164, 106111.

Baskerville, R., \& Grossi, G. (2019). Glocalization of accounting standards: Observations on neo-institutionalism of IPSAS. Public Money \& Management, 39(2), 95-103.

Bell, J., Hoque, Z., Upping, P., \& Oliver, J. (2012). Thai public universities: modernisation of accounting practices. Journal of Accounting \& Organizational Change.

Brusca, I., Caperchione, E., Cohen, S., \& Manes-Rossi, F. (2018). IPSAS, EPSAS and other challenges in European public sector accounting and auditing The Palgrave Handbook of Public Administration and Management in Europe (pp. 165-185): Springer.

Dabbicco, G. (2015). The impact of accrual-based public accounting harmonization on EU macroeconomic surveillance and governments' policy decision-making. International Journal of Public Administration, 38(4), 253-267.

DiMaggio, P. J., \& Powell, W. W. (1991). The new institutionalism in organizational analysis (Vol. 17): University of Chicago Press Chicago, IL.

Elmezughi, A., \& Wakil, A. A. (2018). Feasibility of transformation to accrual basis of accounting in the public sector: Kingdom of Bahrain Context. Academy of Accounting and Financial Studies Journal, 22(6), 1-16.

Fahmid, I. M., Harun, H., Graham, P., Carter, D., Suhab, S., An, Y., . . . Fahmid, M. M. (2019). New development: IPSAS adoption, from G20 countries to village governments in developing countries. Public Money \& Management, 1-4.

Gamayuni, R. R. (2019). THE INITIAL IMPLEMENTATION OF ACCRUAL BASED ACCOUNTING, THE EFFECT ON PERFORMANCE AND FINANCIAL REPORTING QUALITY AT LOCAL GOVERNMENTS IN INDONESIA. Ekspansi: Jurnal Ekonomi, Keuangan, Perbankan dan Akuntansi, 11(1), 13-22.

Gomes, P. S., Fernandes, M. J., \& Carvalho, J. B. D. C. (2015). The international harmonization process of public sector accounting in Portugal: the perspective of different stakeholders. International Journal of Public Administration, 38(4), 268281.

Hair Jr, J. F., Page, M., \& Brunsveld, N. (2019). Essentials of business research methods: Routledge.

Ijeoma, N., \& Oghoghomeh, T. (2014). Determining the contribution of corporate social responsibility on organizational performance. International Journal of Economics, Finance and Management Sciences, 2(1), 84-91.

Ilie, E., \& Miose, N.-M. (2012). IPSAS and the Application of These Standards in the Romania. Procedia-Social and Behavioral Sciences, 62, 35-39.

IPSASB. (2018). IPSASB Proposed Strategy and Work Plan 2019-2023: The International Federation of Accountants New York, NY.

Jorge, S. M., Jesus, M. A., \& Laureano, R. M. (2016). Governmental accounting maturity toward IPSASs and the approximation to national accounts in the European Union. International journal of public administration, 39(12), $976-988$.

Judge, W., Li, S., \& Pinsker, R. (2010). National adoption of international accounting standards: An institutional perspective. Corporate Governance: An International Review, 18(3), 161-174. 
Kaiser, H. F. (1974). An index of factorial simplicity. Psychometrika, 39(1), 31-36.

Kamal Hassan, M. (2008). The development of accounting regulations in Egypt: legitimating the international accounting standards. Managerial Auditing Journal, 23(5), 467-484.

Kaya, D., \& Koch, M. (2015). Countries' adoption of the International Financial Reporting Standard for Small and Mediumsized Entities (IFRS for SMEs)-early empirical evidence. Accounting and Business Research, 45(1), 93-120.

Lampe, H. W., Hilgers, D., \& Ihl, C. (2015). Does accrual accounting improve municipalities' efficiency? Evidence from Germany. Applied Economics, 47(41), 4349-4363.

Matekele, C. K., \& Komba, G. V. (2019). Factors Influencing Implementation of Accrual Based International Public Sector Accounting Standards in Tanzanian Local Government Authorities. Asian Journal of Economics, Business and Accounting, $1-25$.

Mhaka, C. (2014). IPSAS, a guaranteed way of quality government financial reporting? A comparative analysis of the existing cash accounting and IPSAS based accounting reporting. International Journal of Financial Economics, 3(3), 134-141.

Mnif Sellami, Y., \& Gafsi, Y. (2019). Institutional and economic factors affecting the adoption of international public sector accounting standards. International Journal of Public Administration, 42(2), 119-131.

Mustapha, M., Ismail, K. N. I. K., \& Ahmad, H. N. (2017). Contingency For Financial Reporting Quality In The Public Sector Under Cash-Basis IPSAS: A Conceptual Approach.

Nunnally, J. (1978). Psychometric methods: New York: McGraw-Hill.

Patrick, E. A., Danladi, O. A., Caleb, A. J., \& Linda, J. U. (2017). Accountants' perceptions of IPSAS application in Nigerian public sector financial management and reporting. Journal of Economics, Management and Trade, 1-22.

Posner, R. A. (1974). Theories of economic regulation: National Bureau of Economic Research Cambridge, Mass., USA.

Ranjani, R., \& Neba, A. A. (2016). The relationship between governmental performance and participation in public sector accounting and financial processes: the case of IPSAS implementation in Nigeria. Journal of Emerging Trends in Economics and Management Sciences, 7(1), 13-21.

Rossi, F. M., Cohen, S., Caperchione, E., \& Brusca, I. (2016). Harmonizing public sector accounting in Europe: thinking out of the box. Public Money \& Management, 36(3), 189-196.

Sekaran, U., \& Bougie, R. (2016). Research methods for business: A skill building approach: John Wiley \& Sons.

Whitefield, A. A., \& Savvas, P. (2016). The adoption and implementation of the international public sector accounting standards: The challenges faced by the United Nation in producing UN-IPSAS compliant financial reports in Kenya. International Journal of Finance and Accounting, 1(1), 75-91.

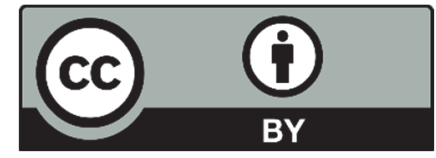

(C) 2020 by the authors; licensee Growing Science, Canada. This is an open access article distributed under the terms and conditions of the Creative Commons Attribution (CC-BY) license (http://creativecommons.org/licenses/by/4.0/). 